\title{
Cultivar and Growing Location Effects on Oil Content and Fatty Acids in Canola Sprouts
}

\author{
Harbans L. Bhardwaj ${ }^{1}$ and Anwar A. Hamama \\ Agricultural Research Station, Virginia State University, P.O. Box 9061, \\ Petersburg, VA 23806
}

Additional index words. Brassica napus, human nutrition, MUFA, PUFA, linoleic fatty acid, linolenic fatty acid, ratio of $\mathrm{C} 18: 2$ to $\mathrm{C} 18: 3$

\begin{abstract}
Although sprouts have played a significant role in human nutrition, there is a lack of information about sprouts made from seed of canola, a new crop in the United States as a source of edible and industrial-use oil. We studied oil content and fatty acid composition in sprouts made from seed of four canola cultivars (Banjo, KS 8200, KS 8227, and Virginia) grown at three locations in Virginia (Orange, Petersburg, and Suffolk) during 2001-2002 and 2002-2003 crop seasons. Canola cultivars exhibited significant effects on contents of oil and all fatty acids except for $\mathrm{C20:0}$, whereas growing locations only affected contents of oil and C22:0, C18:2, and C18:3 fatty acids in the sprouts. The contents of oil and C16:0, C18:0, C20:0 C22:0, C24:0, C16:1, C18:1, C18:2, C18:3, C20:1, C22:1, total saturated, total unsaturated, monounsaturated, and polyunsaturated in canola sprouts were $27.33 \%, 5.38 \%, 1.21 \%, 0.53 \%, 0.27 \%, 0.15 \%$, $0.68 \%, 45.71 \%, 18.35 \%, 8.82 \%, 7.44 \%, 11.46 \%, 7.54 \%, 92.46 \%, 60.18 \%$, and $27.17 \%$ of total fatty acids, respectively. The ratio of $\mathrm{C} 18: 2$ to $\mathrm{C} 18: 3$ fatty acids in canola sprouts averaged 1.00 to 2.09 with Virginia cultivar having the highest ratio (2.33) and KS 8227 having the lowest ratio (1.91). These ratios were within the recommended ratios of 1.00 to 4.00 for optimal human nutrition. Our results indicated that, based only on oil and fatty acid contents, canola sprouts may be healthier than alfalfa, brussels sprout, mungbean, and radish sprouts.
\end{abstract}

We have previously reported that canola sprouts, on an average, contained $27.3 \%$ oil, $25.1 \%$ protein, and $10.8 \%$ crude fiber on a dry weight basis (Bhardwaj and Hamama, 2007) and $0.98,1.23,427,0.57,8.8,430,312,4.54$, $15,607,573$, and $4.89 \mathrm{mg} / 100 \mathrm{~g}$ of aluminum, boron, calcium, copper, iron, potassium, magnesium, manganese, sodium, phosphorus, sulfur, and zinc, respectively (Bhardwaj and Hamama, 2009). In addition, contents of various minerals in canola sprouts were observed to be superior to those in sprouts of alfalfa, brussels sprout, mungbean, and radish based on literature values for these crops. Given that there is a lack of fatty acid profile of canola sprouts in the literature, we are now reporting the contents of various fatty acids in these sprouts.

The term "Canola" is a registered trademark of Canadian Canola Association and refers to cultivars of oilseed rapeseed (Brassica napus L. and B. rapa L.) that produce seed oils with less than $2 \%$ erucic acid (C22:1 fatty acid) and meals with less than $30 \mu \mathrm{mol}$

Received for publication 22 Jan. 2009. Accepted for publication 11 May 2009.

Contribution of Virginia State University, Agricultural Research Station, Journal Article Series No. 269.

Use of any trade names or vendors does not imply approval to the exclusion of other products or vendors that may also be suitable.

${ }^{1}$ To whom reprint requests should be addressed; e-mailhbhardwj@vsu.edu. of aliphatic glucosinolates per gram (Raymer, 2001). Current canola cultivars are essentially free of erucic acid and glucosinolatres. Demand for canola oil is increasing for human consumption as a result of its lowest content of saturated fatty acids ( $5 \%$ to $8 \%$ ) and moderate content of polyunsaturated fatty acids (PUFA).

The objectives of this study were to ascertain affects of cultivars and growing locations on contents of various fatty acids in canola sprouts. In addition, we also evaluated the ratio of omega- 6 to omega- 3 fatty acids [linoleic $(\mathrm{C} 18: 2)$ versus linolenic (C18:3) fatty acids] in canola sprouts resulting from considerable importance of this ratio in human nutrition.

\section{Materials and Methods}

Mature seeds of four canola cultivars (Banjo, KS 8200, KS 8227, and Virginia), grown during each of 2001-2002 and 20022003 crop seasons at three Virginia locations (Orange, Petersburg, and Suffolk), were used in these studies. During the 2001-2002 crop season, the soil type and soil $\mathrm{pH}$ at Orange, Petersburg, and Suffolk locations were: Star silty clay loam and 5.9, Abel sandy loam and 6.2, and Rains fine sandy loam and 5.6, respectively. During the 2002-2003 crop season, the soil type and soil $\mathrm{pH}$ at Orange, Petersburg, and Suffolk locations were Star silty clay loam and 6.9, Abel sandy loam and 6.2, and Rains fine sandy loam and 5.6, respectively. These experiments were conducted at experimental farms of Virginia Tech and Virginia State University. The plots were grown under conventional tillage and fertilized with $100 \mathrm{lb}$ each of nitrogen, phosphorus, and potassium.

Canola seeds ( $20 \mathrm{~g})$, from replications one and two of the original field trial, were sprouted for $6 \mathrm{~d}$ in a wide-mouth jar $(9 \mathrm{~cm}$ $\times 9 \mathrm{~cm} \times 16 \mathrm{~cm}$ ) covered with a mesh screen top to ensure sufficient air ventilation under laboratory conditions $\left(22^{\circ} \mathrm{C}\right.$ temperature and $98 \%$ relative humidity and room lighting, 375 lx for $10 \mathrm{~h}$ ). After initial hydration (seeds were first soaked in water at room temperature overnight), seeds were kept moist by rinsing and draining twice a day and the jars inverted at a slight angle until the next rinse (after 8 to $10 \mathrm{~h}$ ). At the end of sprouting, the fresh weights were recorded and expressed as fresh yield in grams. The sprouts were then dried at $65{ }^{\circ} \mathrm{C}$ until constant weight was reached.

The oil was extracted from $1 \mathrm{~g}$ of ground sprouts at room temperature by homogenization (Dahmer et al., 1989) for $2 \mathrm{~min}$ in $10 \mathrm{~mL}$ hexane/isopropanol $(3: 2, \mathrm{v} / \mathrm{v})$ with a Biospec Model 985-370 Tissue Homogenizer (Biospec Products, Inc. Racine, WI) and centrifuged at $4000 \mathrm{~g}$ for $5 \mathrm{~min}$ as described by Bhardwaj and Hamama (2000). The oil extraction was repeated three times for each sample to ensure full oil recovery and the three extractions were combined. The hexane-lipid layer was washed and separated from the combined extract by shaking and centrifugation with $10 \mathrm{~mL}$ of $1 \% \mathrm{CaCl}_{2}$ and $1 \% \mathrm{NaCl}$ in $50 \%$ methanol. The washing procedure was repeated and the purified lipid layer was removed by aspiration and dried over anhydrous $\mathrm{Na}_{2} \mathrm{SO}_{4}$. The oil content (g/ $100 \mathrm{~g}$ dry basis) was determined gravimetrically after drying under vacuum at $40{ }^{\circ} \mathrm{C}$ and stored under nitrogen at $-10^{\circ} \mathrm{C}$ until analysis.

Fatty acid methyl esters (FAME) were prepared by an acid-catalyzed transestrification method as described by Bhardwaj and Hamama (2000) and Dahmer et al. (1989). The oil samples $(5 \mathrm{mg})$ were vortexed with $2 \mathrm{~mL}$ sulfuric acid/methanol $(1: 99, \mathrm{v} / \mathrm{v})$ in $10-\mathrm{mL}$ glass vials containing a Teflon boiling chip. The open vials were placed in a heating block at $90{ }^{\circ} \mathrm{C}$ until the sample volume was reduced to $0.5 \mathrm{~mL}$. After cooling to room temperature, $1 \mathrm{~mL}$ of hexane followed by $1 \mathrm{~mL}$ of distilled water was added. The mixture was vortexed and the upper hexane layer containing the FAME was taken and dried over anhydrous $\mathrm{Na}_{2} \mathrm{SO}_{4}$. The hexane phase containing FAME was transferred to a suitable vial and kept under $\mathrm{N}_{2}$ at $0{ }^{\circ} \mathrm{C}$ for gas chromatographic analysis.

Analyses of FAME were carried out as described by Bhardwaj and Hamama (2003) using a SupelcoWax 10 capillary column (25 $\mathrm{m} \times 0.25 \mathrm{~mm}$ i.d. and $0.25 \mu \mathrm{m}$ film thickness; SupelcoWax, Inc., Bellefonte, PA) in a Varian model Vista 6000 gas chromatograph equipped with a flame ionization detector (Varian, Sugar Land, TX). An SP-4290 Integrator (Spectra Physics, San Jose, CA) 
was used to determine relative concentrations of the detected fatty acids. Peaks were identified by reference to the retention of FAME standards and quantified by the aid of heptadecanoic acid (17:0) as an internal standard. The concentration of each fatty acid was calculated as a percentage $(\mathrm{w} / \mathrm{w})$ of the total fatty acids.

All data were analyzed by analysis of variance procedures (PROC GLM) in version 6.11 of SAS (SAS, 1996). Fisher's protected least significant difference test was used for mean separation with a significance level of $5 \%$. The oil content and fatty acid composition of canola sprouts was compared with the values for alfalfa, brussels sprouts, mungbean, and radish sprouts reported in Nutrient Database for Standard Reference, Release 14, USDA-ARS Nutrient Data Laboratory (http://www.nal.usda.gov/fnic/foodcomp/).

\section{Results and Discussion}

Because germination is known to enhance series of metabolic and compositional changes in seeds, mainly to supply energy and structural components for growth of new cells (Huang and Grunwald, 1990; Zimmerman, 1971), it has the potential of improving the nutritional quality of grains (Andarwulan et al., 1999; Balasaraswathi and Sadasivam, 1997; Chung et al., 1989).

Analysis of variance (Table 1) indicated that canola cultivars exhibited significant effects on contents of oil and C16:0, C18:0, C22:0, C24:0, C16:1, C18:1, C18:2, C18:3, C20:1, C22:1, total saturated, total unsaturated, monounsaturated, and PUFAs in sprouts, whereas effects of growing locations were significant only for contents of oil, $\mathrm{C} 22: 0, \mathrm{C} 18: 2, \mathrm{C} 18: 3$, and the ratio between $\mathrm{C} 18: 2$ and $\mathrm{C} 18: 3$. The coefficient of determination $\left(R^{2}\right)$ varied from 83 to 99 , whereas $\mathrm{CV}$ varied from 0 to 28 except for the content of C24:0 fatty acid. These observations indicate that conduct of the experiment and statistical analyses were appropriate.

The four canola cultivars differed for all traits under study except for the content of C20:0 fatty acid in sprouts (Table 2). The contents of saturated fatty acids in canola sprouts varied from 7 (KS 8227 cultivar) to $8 \%$ (Banjo cultivar). The saturated fatty acid content in sprouts from KS 8227 and KS 8200 cultivars were similar, both being significantly lower than sprouts from 'Banjo'. Monounsaturated fatty acid (MUFA) contents, among four cultivars, varied from $62 \%$ to $70 \%$, whereas PUFA contents varied from $23 \%$ to $30 \%$. The highest content of PUFA was observed in sprouts made from seeds of the Virginia cultivar, which was similar to the content of that in Banjo cultivar. KS 8200 and KS 8227 cultivars had significantly lower PUFA contents as compared with the other two cultivars. Content of C18:3 fatty acid, a fatty acid desirable for human nutrition, varied from $8 \%$ to $10 \%$ with 'Banjo' ranking number one and 'Virginia' ranking number two. It was interesting to note that both $\mathrm{KS}$ 8200 and KS 8227 cultivars had considerably

Table 1. Partial analysis of variance (mean squares) for composition of sprouts ${ }^{z}$ produced from seed of four canola cultivars grown at three locations in Virginia during 2001-2002 and 2002-2003 crop seasons.

\begin{tabular}{|c|c|c|c|c|c|c|}
\hline \multirow[b]{2}{*}{ Traits } & $\mathrm{L}^{\mathrm{z}}$ & $\mathrm{C}^{\mathrm{z}}$ & $\mathrm{L} \times \mathrm{C}$ & \multirow[b]{2}{*}{$R^{2}$} & \multirow[b]{2}{*}{$\mathrm{CV}(\%)$} & \multirow[b]{2}{*}{ Mean } \\
\hline & & Mean squares & & & & \\
\hline$\overline{\text { Oil }}$ & $44.754 * *$ & $21.588^{*}$ & 1.358 & 83.2 & 7.9 & 27.33 \\
\hline C16:0 & 0.015 & $2.505 * *$ & 0.187 & 91.2 & 7.9 & 5.38 \\
\hline C18:0 & 0.107 & $0.111^{*}$ & 0.37 & 82.7 & 12.7 & 1.21 \\
\hline C20:0 & 0.002 & 0.045 & 0.008 & 75.5 & 22.4 & 0.53 \\
\hline $\mathrm{C} 22: 0$ & $0.026^{*}$ & $0.031 *$ & 0.144 & 93.7 & 28.4 & 0.27 \\
\hline $\mathrm{C} 24: 0$ & 0.007 & $0.145^{* *}$ & 0.026 & 83.3 & 87.0 & 0.15 \\
\hline C16:1 & 0.002 & $0.037 *$ & 0.023 & 87.7 & 13.9 & 0.68 \\
\hline C18:1 & 2.585 & $3365.424 * *$ & 5.900 & 99.5 & 4.3 & 45.71 \\
\hline C18:2 & $5.245^{* *}$ & $88.348 * *$ & 0.885 & 98.0 & 4.2 & 18.35 \\
\hline C18:3 & $0.912 * *$ & $5.848 * * *$ & $0.725 * *$ & 97.4 & 3.7 & 8.82 \\
\hline C20:1 & 1.210 & $514.819^{* *}$ & 0.385 & 99.4 & 12.3 & 7.44 \\
\hline $\mathrm{C} 22: 1$ & 4.868 & $2443.254 * *$ & 1.617 & 99.3 & 18.5 & 11.46 \\
\hline SFA & 0.217 & $1.551 * *$ & 0.183 & 89.3 & 5.2 & 7.54 \\
\hline UFA & 0.217 & $1.541 * *$ & 0.183 & 89.1 & 0.4 & 92.46 \\
\hline MUFA & 3.711 & $162.392 * *$ & $3.153 *$ & 97.6 & 1.7 & 65.28 \\
\hline PUFA & 2.129 & $134.738 * *$ & $3.094 *$ & 97.8 & 3.7 & 27.17 \\
\hline C18:2 /C18:3 & $0.220 * *$ & $0.408 * *$ & 0.013 & 97.8 & 4.2 & 2.09 \\
\hline
\end{tabular}

${ }^{\mathrm{z}} \mathrm{L}=$ location; $\mathrm{C}=$ cultivar. Means over three locations, two replications, and 2 years. All contents are based on dry weight basis.

${ }^{*},{ }^{* *}$ Significant at $5 \%$ and $1 \%$ levels, respectively.

Table 2. Canola cultivar effects on composition of sprouts produced from seed of four cultivars grown at three locations in Virginia during 2001-2002 and 2002-2003 crop seasons.

\begin{tabular}{|c|c|c|c|c|c|c|}
\hline Trait & Banjo & KS 8200 & KS 8227 & Virginia & Mean & $\begin{array}{l}\text { Least significant } \\
\text { difference }(0.05)\end{array}$ \\
\hline$\overline{\text { Oil }}$ & $26.86^{y}$ & $28.05^{y}$ & $28.72^{y}$ & $25.68^{y}$ & 27.33 & 1.92 \\
\hline $\mathrm{C} 16: 0^{\mathrm{z}}$ & 5.85 & 5.23 & 4.81 & 5.61 & 5.38 & 0.38 \\
\hline C18:0 & 1.26 & 1.25 & 1.07 & 1.27 & 1.21 & 0.14 \\
\hline C20:0 & 0.51 & 0.53 & 0.60 & 0.45 & 0.53 & NS \\
\hline $\mathrm{C} 22: 0$ & 0.27 & 0.25 & 0.35 & 0.23 & 0.27 & 0.07 \\
\hline $\mathrm{C} 24: 0$ & 0.08 & 0.12 & 0.32 & 0.10 & 0.15 & 0.12 \\
\hline C16:1 & 0.74 & 0.64 & 0.63 & 0.71 & 0.68 & 0.08 \\
\hline C18:1 & 59.49 & 38.64 & 25.33 & 59.36 & 45.71 & 1.76 \\
\hline C18:2 & 20.00 & 17.46 & 14.95 & 21.00 & 18.35 & 0.69 \\
\hline C18:3 & 9.55 & 8.79 & 7.89 & 9.07 & 8.82 & 0.29 \\
\hline C20:1 & 1.83 & 12.52 & 13.67 & 1.73 & 7.44 & 0.81 \\
\hline $\mathrm{C} 22: 1$ & 0.41 & 14.56 & 30.39 & 0.47 & 11.46 & 1.88 \\
\hline SFA & 7.98 & 7.38 & 7.14 & 7.67 & 7.54 & 0.35 \\
\hline UFA & 92.02 & 92.62 & 92.86 & 92.33 & 92.46 & 0.36 \\
\hline MUFA & 62.48 & 66.36 & 70.02 & 62.26 & 65.28 & 1.02 \\
\hline PUFA & 29.54 & 26.25 & 22.83 & 30.07 & 27.17 & 0.89 \\
\hline C18:2 /C18:3 & 2.12 & 2.00 & 1.91 & 2.33 & 2.09 & 0.08 \\
\hline
\end{tabular}

${ }^{\mathrm{z} F A}=$ fatty acids; SFA = total saturated fatty acids; UFA = total unsaturated fatty acids; MUFA = monounsaturated fatty acids; and PUFA = polyunsaturated fatty acids. All fatty acids expressed as percentage of total of fatty acids.

${ }^{y}$ Means over three locations (Orange, Petersburg, and Suffolk), 2 years, and two replications. All contents are based on dry weight basis.

NS $=$ nonsignificant.

higher content of erucic acid (C22:1) in the sprouts $(15 \%$ and $30 \%$ of total fatty acids in the sprouts, respectively), which would exclude use of sprouts from these cultivars for human consumption given that the U.S. Food and Drug Administration has established 2\% as the upper limit for erucic acid in total fatty acids in edible oil (Raymer, 2001).

Growing locations significantly affected contents of only oil and C22:0, C18:2, and C18:3 fatty acids in canola sprouts (Table 3 ). The average content of C22:0 fatty acids in canola sprouts was less than $0.3 \%$. The content of C18:2 fatty acid was $18 \%, 18 \%$, and $19 \%$ in sprouts made from seed grown at Suffolk, Petersburg, and Orange locations, respectively, with the Suffolk location resulting in the lowest content. The content of C18:3 fatty acid exhibited an opposing trend, whereas the Suffolk location resulted in significantly higher content $(9.1 \%)$ as compared with the content in sprouts made from seed produced in Orange and Petersburg locations being significantly lower contents ( $8.7 \%$ and $8.7 \%$, respectively). The Orange location is in the northern Piedmont region of Virginia and is considered to have cooler temperatures during canola maturity. The Suffolk location, on the other hand, is in the coastal plains region of Virginia and is considered the location with the warmest temperatures during canola maturity. The Petersburg location is in the southern Piedmont region of Virginia and is considered intermediate for temperatures during canola maturity. The results indicate that a move from a cooler to a warmer growing location for canola production is expected to increase the content of $\mathrm{C} 18: 3$ fatty acid and to decrease the content of C18:2 fatty acid. 
Our study indicated interesting results for ratio of content of $n-6$ fatty acids and $n-3$ fatty acids in canola sprouts. In our study, we used the total content of $\mathrm{C} 18: 3$ because we did not differentiate between $n-3$ and n- 6 forms of this fatty acid. Canola cultivars and growing locations significantly affected the ratio of C18:2 to C18:3 fatty acids in canola sprouts (Table 1). As intake of n-6 fatty acids (C18:2) has increased in developed countries, consumption of foods rich in n-3 fatty acids (C18:3) has steadily declined. Omega-3 fatty acids (linolenic, $\mathrm{C} 18: 3$ ) constitute a minuscule portion (less than $1 \%$ ) of the total fatty acids in the U.S. food supply, whereas the omega- 6 fatty acids (linoleic acid, C18:2) constitute a significant majority (Raper et al., 1992; Shukla and Bhattacharya, 2004; Watkins, 2004). The ratio of $n-6$ and n-3 fatty acids is important for human health and is recommended to be $1: 1$ to $4: 1$, whereas in the Western diet, it is now estimated to be $10: 1$ to $30: 1$ (Schmidt, 2001; Watkins, 2004).

The ratio between $\mathrm{C} 18: 2$ and $\mathrm{C} 18: 3$ in canola sprouts averaged 2.09 (Table 2). The ratio of $\mathrm{C} 18: 2$ to $\mathrm{C} 18: 3$ in canola sprouts varied from 1.9 to 2.3 for the four cultivars with sprouts of Virginia cultivar exhibiting the highest ratio, which was significantly greater than the ratio for the other three cultivars (Table 2). The ratios from Orange and Petersburg locations (Table 3) were statistically similar (2.16 and 2.15 , respectively), which were significantly greater than that from the Suffolk location (1.95). These results, similar to those for $\mathrm{C} 18: 2$ fatty acid, suggest that a move from a cooler to a warmer growing location for canola production may decrease the ratio between $\mathrm{C} 18: 2$ and $\mathrm{C} 18: 3$ fatty acids, which is expected to render canola sprouts healthier for human consumption. Overall mean of the C18:2:C18:3 was 2.09, which is within the range of the recommended ratio of $1: 1$ to $4: 1$. Therefore, consumption of canola sprouts is expected to be healthy for human nutrition.

Our results also indicated that canola sprouts may be healthier than alfalfa, brussels sprout, mungbean, and radish sprouts based on the content of oil and C18:3 fatty acid (Table 4). We did not analyze the sprouts made from alfalfa, brussels sprout, mungbean, and radish but used the data for these crops from the Nutrient Database for Standard Reference (USDA, 2007). Canola sprouts contained 2.8, 12.8, 14.6, and 1.1 times more oil, thus providing more energy than alfalfa, brussels sprouts, mungbean, and radish sprouts, respectively. Canola sprouts contained 3.6, 12.4, 51.9, and 1.2 times more C18:3 fatty acid than alfalfa, brussels sprouts, mungbean, and radish sprouts, respectively (Table 4). We were unable to statistically compare the ratio of $\mathrm{C} 18: 2$ with $\mathrm{C} 18: 3$ fatty acids in various sprouts. However, the available information indicated that this ratio was $2.09,0.75,2.20,0.39$, and 1.76 (Table 4) for canola, alfalfa, brussels sprouts, mungbean, and radish sprouts, respectively. The ratios for canola and radish are in the acceptable range of $1: 1$ to $4: 1$ Our results indicate that con-

Table 3. Growing location effects on composition of sprouts produced from seed of four cultivars grown at three locations in Virginia during 2001-2002 and 2002-2003 crop seasons.

\begin{tabular}{|c|c|c|c|c|c|}
\hline Trait & Orange & Petersburg & Suffolk & Mean & $\begin{array}{l}\text { Least significant } \\
\text { difference }(0.05)\end{array}$ \\
\hline$\overline{\text { Oil }}$ & $26.00^{y}$ & $26.79^{y}$ & $29.21^{\mathrm{y}}$ & 27.33 & 1.67 \\
\hline $\mathrm{C} 16: 0^{z}$ & 5.36 & 5.41 & 5.36 & 5.38 & NS \\
\hline C18:0 & 1.30 & 1.14 & 1.19 & 1.21 & NS \\
\hline C20:0 & 0.53 & 0.51 & 0.53 & 0.53 & NS \\
\hline $\mathrm{C} 22: 0$ & 0.30 & 0.30 & 0.23 & 0.27 & 0.06 \\
\hline $\mathrm{C} 24: 0$ & 0.18 & 0.15 & 0.14 & 0.15 & NS \\
\hline C16:1 & 0.69 & 0.68 & 0.67 & 0.68 & NS \\
\hline C18:1 & 46.13 & 45.33 & 45.66 & 45.71 & NS \\
\hline C18:2 & 18.85 & 18.47 & 17.73 & 18.35 & 0.60 \\
\hline C18:3 & 8.70 & 8.67 & 9.10 & 8.82 & 0.25 \\
\hline C20:1 & 7.13 & 7.53 & 7.65 & 7.44 & NS \\
\hline $\mathrm{C} 22: 1$ & 10.82 & 11.81 & 11.74 & 11.46 & NS \\
\hline SFA & 7.67 & 7.51 & 7.45 & 7.54 & NS \\
\hline UFA & 92.33 & 92.49 & 92.55 & 92.46 & NS \\
\hline MUFA & 64.77 & 65.35 & 65.73 & 65.28 & NS \\
\hline PUFA & 27.56 & 27.14 & 26.93 & 27.17 & NS \\
\hline C18:2 /C18:3 & 2.16 & 2.15 & 1.95 & 2.09 & 0.07 \\
\hline
\end{tabular}

${ }^{\mathrm{z} F A}=$ fatty acids; SFA = total saturated fatty acids; UFA = total unsaturated fatty acids; MUFA = monounsaturated fatty acids; and PUFA = polyunsaturated fatty acids. All fatty acids expressed as percentage of total of fatty acids.

${ }^{\mathrm{y}}$ Means over four cultivars (Banjo, KS 8200, KS8227, and Virginia), 2 years, and two replications. All contents are based on dry weight basis.

NS = nonsignificant.

Table 4. Composition of canola sprouts relative to composition of sprouts of alfalfa, brussels sprout, mungbean, and radish.

\begin{tabular}{|c|c|c|c|c|c|}
\hline Trait & Canolaw $^{w}$ & Alfalfa $^{x}$ & Brussels sprout $^{\mathrm{x}}$ & Mungbean $^{\mathrm{x}}$ & $\operatorname{Radish}^{x}$ \\
\hline$\overline{\text { Oil }}$ & 27.33 & 9.61 & 2.14 & 1.87 & 25.48 \\
\hline $\mathrm{C} 16: 0^{\mathrm{z}}$ & 5.38 & 0.82 & 0.38 & 0.33 & 6.68 \\
\hline C18:0 & 1.21 & 0.11 & 0.02 & 0.08 & 0.96 \\
\hline C20:0 & 0.53 & $-\mathrm{y}$ & - & - & - \\
\hline $\mathrm{C} 22: 0$ & 0.27 & - & - & - & - \\
\hline $\mathrm{C} 24: 0$ & 0.15 & - & - & - & - \\
\hline C16:1 & 0.68 & 0.00 & 0.01 & 0.00 & 0.07 \\
\hline C18:1 & 45.71 & 0.78 & 0.14 & 0.23 & 4.12 \\
\hline C18:2 & 18.35 & 3.26 & 0.32 & 0.44 & 4.13 \\
\hline C18:3 & 8.82 & 2.44 & 0.71 & 0.17 & 7.27 \\
\hline C20:1 & 7.44 & 0.00 & 0.00 & 0.00 & - \\
\hline $\mathrm{C} 22: 1$ & 11.46 & 0.00 & 0.00 & 0.00 & - \\
\hline SFA & 7.54 & 0.96 & 0.44 & 0.48 & 7.72 \\
\hline UFA & 92.46 & 6.48 & 1.26 & 0.83 & 15.71 \\
\hline MUFA & 65.28 & 0.78 & 0.16 & 0.23 & 4.22 \\
\hline PUFA & 27.17 & 5.70 & 1.09 & 0.60 & 11.49 \\
\hline C18:2 /C18:3 & 2.09 & 0.75 & 2.20 & 0.39 & 1.76 \\
\hline
\end{tabular}

${ }^{\mathrm{z}}$ All fatty acids expressed as percentage of total of fatty acids.

ynknown.

${ }^{x}$ Values from Nutrient Database for Standard Reference, Release 14. USDA-ARS Nutrient Data Laboratory (http://www.nal.usda.gov/fnic/foodcomp/). Reviewed 5 May 2009. The values in this publication are grams per $100 \mathrm{~g}$ fresh weight. These values were converted to dry weight basis for this table. ${ }^{\text {w}}$ Average of four cultivars (Banjo, KS 8200, KS 8227, and Virginia), grown at three locations (Orange, Petersburg, and Suffolk) in Virginia over 2001-2002 and 2002-2003 crop seasons. All contents are based on a dry weight basis.

SFA = total saturated fatty acids; UFA = total unsaturated fatty acids; MUFA = monounsaturated fatty acids; and PUFA = polyunsaturated fatty acids. All fatty acids expressed as percentage of total of fatty acids.

sumption of canola sprouts may be helpful in achieving a balance between C18:2 and C18:3 fatty acids and may lead to better management of inflammatory and autoimmune diseases, coronary heart disease, depression, arthritis, aging, and cancer as suggested by Simopoulos and Robinson (1998). Additionally, addition of canola sprouts to the human diet could also provide an alternative to use of encapsulated fish oils as a result of their higher degree of oxidation (Shukla and Bhattacharya, 2004). Finally, our results may provide a potential means of correcting many behavioral, learning, memory, and neurological human disorders as per suggestions of Watkins (2004) indicating that insufficiency of n-3 fatty acids in the diet may be a cause of increased incidence of such diseases.

Overall, our results indicate quality of canola sprouts, based on their oil and fatty acid contents, is governed more by the cultivars than the growing location. We also observed that close attention needs to be paid to the canola cultivar used to grow sprouts to ensure that the content of erucic acid in the oil in canola sprouts is less than $2 \%$. 


\section{Literature Cited}

Andarwulan, N., D. Fardiaz, G.A. Wattimena, and K. Shetty. 1999. Antioxidant activity associated with lipid and phenolic mobilization during seed germination of Pangium edule Reinw. J. Agr. Food Chem. 47:3158-3163.

Balasaraswathi, R. and S. Sadasivam. 1997. Changes in oil, sugars and nitrogenous components during germination of sunflower seeds, Helianthus annuus. Plant Foods Hum. Nutr. 51:71-77.

Bhardwaj, H.L. and A.A. Hamama. 2000. Oil, erucic acid, and glucosinolate contents in winter hardy rapeseed germplasms. Ind. Crops Prod. 12:33-38.

Bhardwaj, H.L. and A.A. Hamama. 2003. Accumulation of glucosinolate, oil, and erucic acid contents in developing Brassica seeds. Ind. Crops Prod. 17:47-51.

Bhardwaj, H.L. and A.A. Hamama. 2007. Yield and nutritional quality of canola sprouts. HortScience 42:1656-1658.
Bhardwaj, H.L. and A.A. Hamama. 2009. Effect of cultivar and growing location on the mineral composition of canola sprouts. HortScience 44:508-511

Chung, T.Y., E.N. Nwokolo, and J.S. Sim. 1989. Compositional and digestibility changes in sprouted barley and canola seeds. Plant Foods Hum. Nutr. 39:267-278.

Dahmer, M.L., P.D. Fleming, G.B. Collins, and D.F. Hildebrand. 1989. A rapid screening technique for determining the lipid composition of soybean seeds. J. Am. Oil Chem. Soc. 66:543-549.

Huang, L.S. and C. Grunwald. 1990. Lipid and fatty acid changes during germination of alfalfa seeds. Phytocem. 29:1441-1445.

Raper, N.R., F.J. Cronin, and J. Exler. 1992. Omega-3 fatty acid content of the US food supply. J. Amer. Coll. Nutr. 11:304-308.

Raymer, P.L. 2001. Canola: An emerging oilseed crop, p. 122-126. In: Janick, J. and A. Whipkey (eds.). Trends in new crops and uses. ASHS Press, Alexandria, VA.
SAS. 1996. SAS System for Windows. SAS Institute, Inc., Cary, NC.

Schmidt, M.A. 2001. Brain-building nutrition, the healing power of fats and oils. 2nd Ed. North Atlantic Books, Berkeley, CA.

Shukla, V.K.S. and K. Bhattacharya. 2004. Correcting $\omega 6 / \omega 3$ balance in human diet by internally stabilized designer oil. AgroFOOD Industry Hi-Tech 3:41-43.

Simopoulos, A.P. and J. Robinson. 1998. The omega plan. Harper Collins, New York, NY. p. $350-353$.

USDA. 2007. USDA National Nutrient Database for Standard Reference, Release 21. (Nutrient Data Laboratory Home Page). 9 June 2009. $<\mathrm{http} / / /$ www.ars.usda.gov/nutrientdata $>$.

Watkins, C. 2004. Fundamental fats. Inform 15:638-640.

Zimmerman, D.C. 1971. Metabolism of fatty acids during seed germination. Proc. of the Flax Institute US. 41:19-20. 